\title{
Towards a Theoretical Model for Strategic Assets, Competitive Capabilities and Firm Performance: A Research Agenda
}

\author{
Justus Kyengo, James Kilika \\ Department of Business Administration, Kenyatta University, Nairobi, Kenya \\ Email address: \\ Justus.kyengo@gmail.com (J. Kyengo),kilika.james@ku.ac.ke (J. Kilika)
}

To cite this article:

Justus Kyengo, James Kilika. Towards a Theoretical Model for Strategic Assets, Competitive Capabilities and Firm Performance: A Research Agenda. Science Journal of Business and Management. Vol. 5, No. 2, 2017, pp. 45-53. doi: 10.11648/j.sjbm.20170502.11

Received: January 9, 2017; Accepted: January 24, 2017; Published: March 9, 2017

\begin{abstract}
Each firm faces a unique set of competitors when similarities among products and resources are considered to identify competitors. Despite much debate in the strategy literature on strategic assets, competitive capabilities and firm performance, little consensus has been generated. Thus, the gap the current paper seeks to fill. The study's objectives are as follows; to review the extant theoretical literature on strategic assets, competitive capabilities and firm performance, to review the extant empirical literature on strategic assets, competitive capabilities and firm performance, to identify the gaps in literature that will help in understanding the relationship between strategic assets, competitive capabilities and firm performance and to propose a theoretical framework based on the identified theoretical and empirical gaps. This study will be important in terms of empirical enhancement since past studies have limitation of the empirical research on strategic assets and competitiveness in regards to being imperfect comparability of results across different studies using different variables (features) describing competitiveness. This paper contributes to the theoretical research on strategic assets, competitive capabilities and firm performance not only by the synthesis of old and new writings as well as the findings of the exploratory studies, but also by concept synthesis. Since the concept of strategic assets and competitive capability can be reported to individual product/service, enterprise/farm, industry, economic sector, region, nation or international economic blocks, the attempts towards creating one common definition of strategic assets, competitive capabilities seem to be doomed to fail. This study is significance because it will be used in the developing of government policies on strategic assets, competitive capabilities and its links to performance which requires an understanding of the major factors that facilitate or impede firms' ability to compete. These factors can, however, differ depending on a country, region or industry. This study will facilitate polices on public spending and taxes, exchange rates, interest rates, and government regulatory activities as some of the examples of key macroeconomic determinants of competitiveness.
\end{abstract}

Keywords: Strategic Assets, Competitive Capabilities, Competitive Advantage, Resource heterogeneity, Organization's Capability and Firm Performance

\section{Introduction}

The issue of firm performance has been central in strategy research for decades and encompasses most other questions that have been raised in the field, as for instance, why firms differ, how they behave, how they choose strategies and how they are. With the rise of the resource-based approach, strategy researchers' focus regarding the sources of sustainable competitive advantage shifted from industry to firm specific effects whereby competitive capabilities and firm performance was looked at from assets or resources (Acedo, Barroso \& Galan, 2006). A central premise of the resource-based view is that firms compete on the basis of their resources or strategic assets and capabilities (Barney, 2012). Most resource-based view researchers choose to look within the enterprise and down to the factor market conditions that the enterprise must contend with, to search for some possible causes of sustainable competitive advantages holding constant all external environmental factors (Barney, 2012). 
There is also a sense that the ebb and flow of strategy research may have swung excessively to firm-centered analyses and has tended to ignore industry dynamics (Woiceshyn \& Daellenbach, 2005). Zahra, Sapienza and Davidson argue that resources are not valuable in and of themselves, but because they allow firms to perform activities that create advantages in particular markets [29]. The competitive value of resources can be enhanced or eliminated by changes in technology, competitor behavior, or buyer needs which an inward focus on resources will overlook. Similarly, Helfat and Raubitschek argue that many organizational capabilities emerge, are refined, or decay as a result of, or an absence of, product market activity. Firm's strategic resources are seen as the fundamental determinants of competitive advantage and performance. Firms within an industry or within a strategic group may be heterogeneous with respect to the bundle of resources that they control [16].

Resource heterogeneity may persist over time because the resources used to implement firms' strategies are not perfectly mobile across firms for example some of the resources cannot be traded in factor markets and are difficult to accumulate and imitate. Resource heterogeneity or uniqueness is considered a necessary condition for a resource bundle to contribute to a competitive advantage. The argument goes "If all firms in a market have the same stock of resources, no strategy is available to one firm that would not also be available to all other firms in the market" (Ordaz, Alcazar \& Cabrera, 2003). Performance differentials are viewed as derived from rent differentials, attributable to resources having intrinsically different levels of efficiency in the sense that they enable the firms to deliver greater benefits to their customers for a given cost or can deliver the same benefit levels for a lower cost (Barney \& Hesterly, 2008). The assumed heterogeneity and immobility are not, however, sufficient conditions for sustained competitive advantage. According to Barney a firm resource must, in addition, be valuable, rare, and imperfectly imitable and substitutable in order to be source of a sustained competitive advantage [4].

Firms constantly take offensive and defensive strategic actions vis-à-vis competitors Porter (2011) thus modifying the competitive environment. On the other hand, strategy is dependent on and constrained by the controlled resources path dependency and strategy coordinates the development and protection of existing resources and the creation or acquisition of new resources, taking into account the competitive environment. Anderse'n argues that firms often engage in complex and simultaneous competitivecollaborative relationships. He sees cooperation and competition as distinct, orthogonal constructs and not as opposite ends of a single continuum: firms may work together in some domains and at the same time compete by taking independent actions in other domains, focusing on behavioral aspects of competition and cooperation [2]. Chang and Hou explain that firms combining high levels of competitive and cooperative orientations will generate higher rents because of greater knowledge development, economic and market growth and technological progress [9]. In Barney and Hesterly, (2008) definition, economic value is determined by factors exogenous to the RBV, namely the perceived benefits gained by customers and resource costs. So, based on their perception of the usefulness of the product on offer, customers determine their perceived benefits.

Similarly, the bargaining power of resource suppliers (external suppliers of resources and employees) affects the firm's competitive advantage because it influences the economic cost of the acquired resource. In turn, a resource supplier's bargaining power depends on the perceived value of the resource to the firm (Galbreath, 2004). Eisenhardt and Martin argue that, although Barney's definition may be more precise theoretically, it is virtually impossible to meaningfully operationalize quantitatively. They explain that the time frame that determines the sustainability of competitive advantage may vary from industry to industry depending on such exogenous variables as product life cycles, patent protections, copyrights, or other variables specific to an industry [13].

Firm performance, viewed here as profit in excess of the cost of capital, depends upon the attractiveness of the industry in which the firm operates (industry-effect on performance) and the firm's competitive advantage. Having a competitive advantage does not lead automatically to higher performance by comparison with the breakeven competitor in the industry. What fraction of the value linked to competitive advantage is appropriated by the firm depends on the firm's product price. On the one hand, product pricing is part of the firm's strategy. On the other hand, when choosing its product price the firm is influenced by its competitive environment, in particular by the bargaining power of customers and by the current prices of competitors and the expected reactions of competitors to the chosen price.

Helfat and Raubitschek mention three basic types of strategies to raise rivals' costs using firm resources: the monopolization of resources, the use of differentiation to have a privileged access to resources, and the use of political strategies. The first type of strategy points to a firm restricting output in the product market by using market power with regard to a resource that is necessary to competitors [16]. This kind of behavior is called vertical market foreclosure by economists and can be achieved in several ways of which vertical integration (Prescott, 2011), long-term contracts and exclusive dealing agreements (Rainbird, 2010). The second strategy is to obtain a reputation and public recognition as a high status firm. With this high status, firms have been demonstrated to have particular access to low cost capital and unique pricing benefits (Zahra, Sapienza \& Davidsson, 2006). Reputation is a firm intangible assets that needs to be accumulated over time. Consequently, it is not readily available to new entrants. The third strategy consists in lobbying government(s) to influence regulations that preclude competitors from using a resource (Zahra, Sapienza \& Davidsson, 2006). Some assets fall short of being sources of sustained performance because substitutes of these resources exist or may be developed rapidly. Firms may act upon the rent-producing potential of 
these strategic assets by engaging in political strategies that restrict the set of substitutes available to competitors. This explains why firms may engage in political activities to affect industry level regulations: these regulations will have a differential impact on the industry participants according to their bundles of strategic assets.

Resources that are sources of sustainable competitive advantage and superior profits are called strategic assets and strategic assets are intangible. These resources are simultaneously valuable, rare, inimitable, non-substitutable, heterogeneous, immobile, ex post limits to competition and ex ante limits to competition (Woiceshyn \& Daellenbach, 2005). Intangible assets have been argued to be strong contributors to a firm's success by virtue of their inimitable properties (Acedo, Barroso \& Galan, 2006). Compared to tangible assets, Galbreath (2004) confirmed that intangibles such as organizational and reputation assets do contribute more significantly to a firm's success than tangible assets. Strategic assets should meet the following criteria; valuable resources in order to be strategic; it must have the capacity to improve the company's efficiency and effectiveness; rare resources which are strategic to the extent that they are rare and demand for them is high; imperfectly imitable resources and non-substitutability meaning that competitors cannot find a substitute for what it can do.

The strategic assets' characteristics imply that sources of sustainable competitive advantage are often related to intangible resources. Intangible resources, also named knowledge, invisible assets, absorptive capabilities (Foss \& Knudsen, 2009), core competencies, strategic assets, core capabilities (Galbreath, 2004), intellectual property rights, trademarks, information technology such as databases, networks and skills such as capabilities and competencies (Anderse'n, 2007), organizational memory (Eisenhardt \& Martin, 2010) or any other denomination with a similar meaning, and intangible resources are such as reputation and brand name, employee know-how, customer loyalty, social relationship, culture, employees' expertise and their commitment and loyalty, technology among others. Prescott (2011) observes that technology, accumulated consumer information, brand name, reputation and corporate culture are intangible assets which are invaluable to the firm's competitive power, and also the only real source of competitive edge that can be sustained over time.

\section{Statement of the Problem}

Researchers' attention has often focused on competition in product markets. For instance, Porter's analysis concentrates on the firms' competitive interactions on the 'demand side'. However, firms compete simultaneously on the 'resource side'. Taking into account the different competition processes enriches competitor analysis. As highlighted by Galbreath (2004) and Ordaz, Alcazar and Cabrera (2003), each firm faces a unique set of competitors when similarities among products and resources are considered to identify competitors.
Firms may adopt several kinds of competitive capabilities. First, firms may take actions or responses that aim at improving their position vis-à-vis rivals by increasing their efficiency or by hurting competitors for example by damaging competitors' performance. Second, firms may act/respond friendly to some rivals in order to foster collusion, to avoid harmful retaliatory moves from these competitors or to achieve gains from cooperation. As emphasized by the RBV, resources may help to increase efficiency by decreasing costs and increasing customers' willingness-to-pay for the firm's product. If the firm transfers some of the efficiency gain to its customers for example increasing customer surplus for the firm's product, it will improve its competitive position with respect to the other firms in the product market. Besides using strategic assets to improve its efficiency, a firm may leverage its resources to hurt competitors. A firm adopts such a behavior if it perceives the relationship with the competitor as a zero-sum game where one firm's gain is another firm's loss. The firm may raise rivals' costs, decrease buyers' willingness-to-pay for rivals' products or adopt pricing predatory behaviors.

Numerous authors in the competitive dynamics literature recognize the importance of strategic assets for competitive behavior. For instance, Chang and Hou (2007) consider firm resources as one determinant of the firm capacity to respond; Carmen, Fernando and Ramon (2003) study the impact of strategic similarity for example the similarity in the general pattern of resource deployments and competitive orientations on rivalry; Teece (2007) compare firms along two dimensions, market commonality and resource similarity; Helfat and Raubitschek (2007) identify asset similarity and organizational structure of competing firms as factors moderating the relationship between multimarket contact and the intensity of competition; Galbreath (2004) finds support for the operationalization of the strategic importance of market to firms with the dimension of resource centrality; linking multimarket competition and resource allocation, Carmen, Fernando and Ramon (2003) suggest that a firm can strategically use its corporate-level resources allocation to reconfigure its competitive context by influencing other firms' resource allocations.

On the other hand many empirical articles tend to use the theoretical perspective of dynamic capabilities only as an explanation approach without enhancing or even referencing the concept of dynamic capabilities in their empirical work. The theory of dynamic capabilities involves various processes and has thus far failed to provide clear constructs (Zahra et al., 2006). Some theoretical articles hint at an influence of the configuration of dynamic capabilities on firm performance but providing no clear concept. The quality aspect of dynamic capabilities and its impact on firm performance represent a clear research gap. While there has been much debate in the strategy literature on strategic assets, competitive capabilities and firm performance this debate has generated little consensus. It is also clear from past research that much more is need in terms of new works relating to theoretical model for strategic assets, competitive capabilities 
and firm performance. This provides a knowledge gap that the current paper seeks to fill.

\section{Literature Review}

Carmen, Fernando and Ramon argued that corporate success or failure is explained by the match of an organization's capabilities to the challenges faced in the business environment. They stated that a distinctive capability consists of a unique set of relationships and contracts between a firm and its stakeholders, which competitors cannot readily imitate; and these relationships are usually based on reputation, architecture or innovation, or a combination of the three. They also argued that distinctive capabilities lead to competitive advantage when they are applied to an industry and brought to a market [8]. Capabilities, by their very nature are intangible. They refer to a firm's capacity in using, treating and developing their resources for a specific purpose or objective; and this capacity is obtained from the firm's experiences, tacit knowledge, and unique complex of combinations of the firm's resources, and the firm's competitive advantage is based on its ability to respond to evolving opportunities which depends on business processes or capabilities. Businesses' success or failure depends on a firm's ability in choosing the right capabilities to build, managing them carefully and exploiting them fully (Woiceshyn \& Daellenbach, 2005).

Capabilities should be rare because competitors must find them difficult to emulate; they are complex because they are explained by a number of linked factors as in the creation of superior customer value, and they are tacit because they are inextricably embedded in organizational experience and practice (Acedo, Barroso and Galan, 2006). Capabilities are developed via learning processes when the firm's employees repeatedly apply their knowledge to solving the firm's marketing problems. An important aspect of developing capabilities is the ways in which knowledge is integrated. Thus, capabilities can be thought of as integrative processes by which knowledge-based resources and tangible resources come together to create valuable outputs.

Assets have a rent-producing potential if they contribute alone or bundled with other resources to building competitive advantage for example superior differentiation and/or lower costs by comparison with the marginal competitor in the product market. This rent-producing potential is sustained as long as the resource or bundle of resources on which the competitive advantage is based is immobile and not made obsolete by environmental changes. Resources with a sustained rent-producing potential are referred to as strategic resources. Foss and Knudsen says that most contributions within the RBV take the individual resource as the relevant unit of analysis to study competitive advantage. However, they points out that this choice may only be legitimated if the relevant resources are sufficiently well-defined and freestanding. If, in contrast, there are strong relations of complementarity and cospecialization among resources, it is the way resources are clustered and how they interplay that is important to the understanding of competitive advantage [14].

If the firm's strategy does not set up the correct structure, control systems and reward systems to support the resource, it seems highly improbable that the resource will contribute to the firm's competitive advantage. Asset immobility (or imperfect mobility) points to the existence of factor market imperfections as a necessary condition for the sustainability of competitive advantage. Immobility includes imperfect imitability and substitutability; the conditions for sustainability. Barriers to resource mobility, also called isolating mechanisms or resource position barriers, are economic forces that limit the extent to which a competitive advantage can be duplicated or neutralized through the acquisition, imitation or substitution by competitors of the resources on which this advantage is built (Helfat \& Raubitschek, 2007).

In addition to building competitive advantage, resources may increase the firm's capacity to charge high prices and, thus, contribute to performance by helping the firm to appropriate the value linked to competitive advantage. Furthermore, assets may be used to erect entry barriers and so increase performance at the industry level for example all industry players included the breakeven competitor. For instance, a firm may use its lobbying capability to prompt the government to erect entry barriers that enable the firms in the industry to charge high prices once output has been restricted. Note that industry competitors will be able to freeride on the firm's expenses to build entry barriers.

To be source of competitive advantage for its buyer an asset traded on a market must generate rents that the firm is able to appropriate. This will be the case when the firm purchases the resource for less than its marginal productivity when used in combination with the firm's stock of other. Because the asset may have a different marginal productivity in different industries, the presence of buyers from other industries in the resource market may raise the resource price above the firm's reservation. The firm may then turn to internal asset creation. The firm will be able to purchase the resource for less than its marginal productivity when it possesses superior information, has bargaining power on the resource supplier or is lucky. Carmen, Fernando and Ramon (2003) discuss the conditions for imperfectly mobile resources to be gainfully traded between firms and the transaction cost problems linked to trading imperfectly mobile resources.

Performance, viewed here as profit in excess of the cost of capital, depends upon the attractiveness of the industry in which the firm operates (industry-effect on performance) and the firm's competitive advantage. Having a competitive advantage does not lead automatically to higher performance by comparison with the breakeven competitor in the industry. What fraction of the value linked to competitive advantage is appropriated by the firm depends on the firm's product price. On the one hand, product pricing is part of the firm's strategy. On the other hand, when choosing its product price 
the firm is influenced by its competitive environment, in particular by the bargaining power of customers and by the current prices of competitors and the expected reactions of competitors to the chosen price.

Firm performance is a concept that supports the effective and efficient use of financial resources to achieve overall company objectives which include both shareholders wealth maximization and profit maximization objectives. It can be measured using long term market performance measures and other performance measures that are non-market-oriented measures or short term measures. Performance can be seen here as the success in meeting pre-defined objectives, targets and goals. Firm performance is thus the effectiveness of a firm in achieving the outcomes it intends to achieve within specified time targets. These outcomes can be explained as the measures by which the firm is evaluated, and broadly include the quality of governance (Zahra, Sapienza \& Davidsson, 2006).

\section{Theoretical Review}

This paper was guided by three theories thus resource dependence theory which is the study of how the external resources of organizations affect the behavior of the organization. The procurement of external resources is an important tenet of both the strategic and tactical management of any company. Resource dependence theory has implications regarding the optimal divisional structure of organizations, recruitment of board members and employees, production strategies, contract structure, external organizational links, and many other aspects of organizational strategy (Davis \& Cobb, 2010). Resource dependency theory has been proposed by organization theorists Jeffrey Pfeffer and Salancik who explain organizations in terms of their interdependence with their environment (Daft, 2003). The degree or extent of this resource dependency varies from one organization to the next. For example, a financial organization such as a bank will depend heavily on the outside environment for money, while another organization such as a manufacturing plant may depend more on the quality and availability of personnel. The basic argument of resource dependence theory can be summarized as organizations depend on resources, these resources ultimately originate from an organization's environment and that the environment, to a considerable extent, contains other organizations. According to this theory the resources one organization needs are thus often in the hand of other organizations, resources are a basis of power, legally independent organizations can therefore depend on each other and that power and resource dependence are directly linked organization A's power over organization B is equal to organization B's dependence on organization A's resources. Lastly it is that power is thus relational, situational and potentially mutual. Resource dependency theory focuses on a firm's need to access resources from other actors in the environment and describes how resource scarcities force organizations to pursue new innovations that use alternative resources (Hessels, \& Terjesen, 2010).

Institutional arguments rely not on aggregations of individual action, or on patterned interaction games between individuals, but on "institutions that structure action (Clemens \& Cook, 2005). Institutions are emergent, "higherorder" factors above the individual level, constraining or constituting the interests and political participation of actors without requiring repeated collective mobilization or authoritative intervention to achieve these regularities (Jepperson, 2001). Institutional arguments are not about aggregations of individual action, but higher-order factors above the individual level that influence political processes and outcomes and tend to produce regular patterns or stasis. Institutional theory provides a theoretical lens through which researchers can identify and examine influences that promote survival and legitimacy of organizational practices, including factors such as culture, social environment, regulation (including the legal environment), tradition and history, as well as economic incentives, whilst acknowledging that resources are also important (Baumol et al., 2009). According to Institutional Theory external social, political, and economic pressures influence firms' strategies and organizational decision-making as firms seek to adopt legitimate practices or legitimize their practices in the view of other stakeholders. It can be used to explain how changes in social values, technological advancements, and regulations affect decisions regarding 'green' sustainable activities (Brunton et al., 2010) and environmental management. It describes the three forms of drivers that create isomorphism in organizational strategies, structures and processes.

Dynamic capabilities theory adds to the resource based view by attempting to improve theory by explaining the nature of sustainable competitive advantage, while also intending to inform managerial practices. In essence the DCT tries to make use of competences that are unique to firms to gain competitive advantage and explains how these competences are developed, deployed and protected. The approach explains that the way organizations develop firm specific competences to respond to changes in the business environment is ultimately related to the firm's business processes, market positions, and opportunities. The DCT views competition in Schumpeterian terms, where firms are constantly seeking to create new combinations and competitors in the marketplace are continuously attempting to improve their competences or to imitate the competence of their most qualified competitors. Rivalry is thus inevitable in Schumpeterian terms, which implies that a firm's ability to improve or develop new types of competences is imperative in developing long-term competitive advantage (Ambrosini \& Bowman, 2009).

From the theoretical review the study findings indicate that Eisenhardt and Martin, suggests that dynamic capabilities are not abilities but processes to address or initiate market change [13]. Zahra and George (2002) regard dynamic capabilities neither as a firm's abilities nor as processes but as capabilities to match customer demands and competitor 
strategies routines. Helfat and Raubitschek (2000) give further support for the idea that dynamic capabilities are embedded in organizational processes. Eisenhardt and Martin comment that dynamic capability processes comprise specific and identifiable routines which have been extensively researched. In particular, they suggest that several processes can be used as examples of dynamic capabilities such as product development (combining various skills in crossfunctional teams), strategic decision making (pooling of diverse business, functional and personal expertise), alliance and acquisitions routines (new resources, pre- and postacquisition routines) and many others [13].

Zahra et al. argue that the mere existence of dynamic capabilities in a firm does not result in competitive advantages or high performance. The relationship results from the idea that dynamic capabilities originate and define the firm's individual resource configuration, which shapes the firm's competitiveness and therefore performance [30]. Zahra, Sapienza and Davidsson view e-commerce as higherorder capability that requires alignment among organizational factors, changing technology and business environments. Consistent with IT-related RBV literature, e-business serves as a resource enabler or catalyst that supports organizations in reconfiguring resources and capitalizing on opportunities to adapt to the fast-changing environment [29].

\section{Theoretical Presentation}

This study was guided by three main variables, strategic assets, firm competitive capabilities and firm performance. Strategic assets and firm competitive capabilities are the independent variables while firm performance is the dependent variable. Firm's culture is the mediating variable. This relationship among the variables is shown in the below diagram.

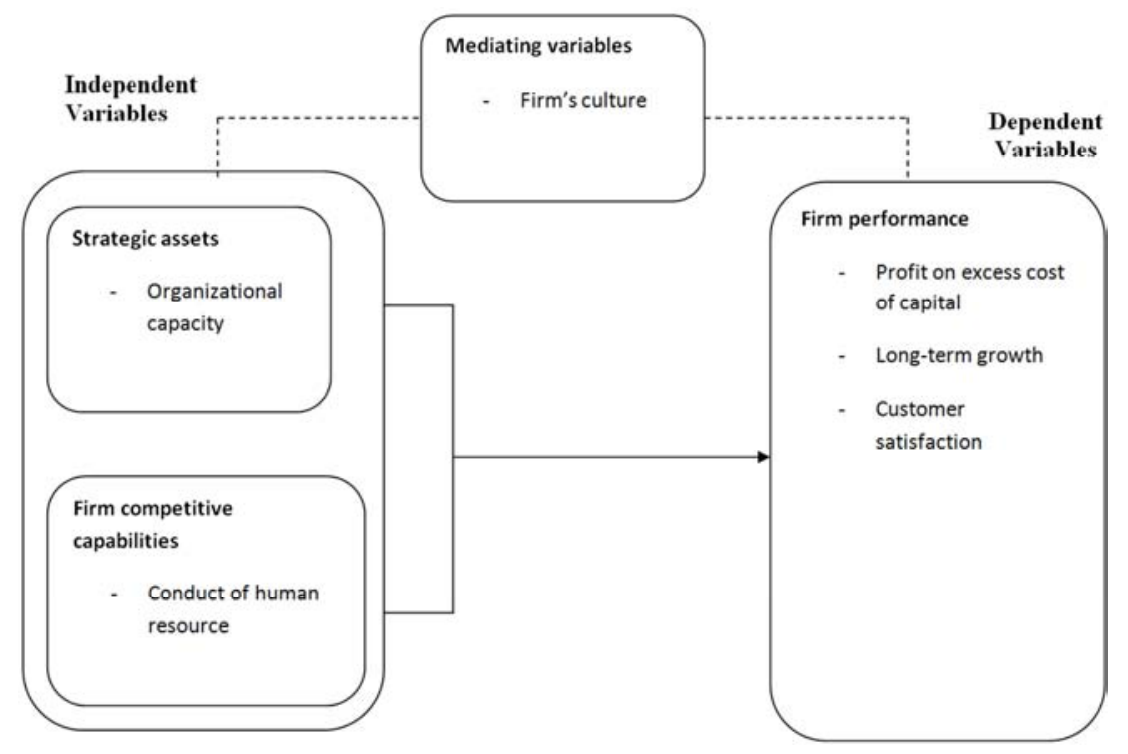

Figure 1. Conceptual framework.

\section{Empirical Review}

Johansen and Vahlne (2009) did a study on the statistical relationship between the resource asymmetry results and the scale efficiency and market power contexts. The purpose of the study was the analysis of interactions is to determine whether firms tend to redeploy especially strong resources when the traditional scale efficiencies or market power explanations for horizontal acquisitions appear to apply. If both the main effect of resource asymmetry and the interactive effect of resource asymmetry are positive and significant, then the results would suggest that resource asymmetry is a common feature of resource redeployment and is especially strong in specific acquisition contexts. If the interactive effect of resource asymmetry was not only significant but also replaced the main effect of resource asymmetry, then the results would suggest that resource asymmetry applies only to specific acquisition contexts. The results were that such knowledge about foreign business environments is however to a large extent tacit, and must therefore be gained experientially through actual operations in the pertinent locations and by engaging with local business partners. The limitation of this study was that the purpose of the article was not made clear in the introduction and the statistical methods used were not appropriate.

Santangelo and Meyer (2011) and Johansen and Vahlne, 2009) carried out a study on the extent to which managerial resources are the foundation for higher level capabilities. The purpose of the study was to find out the relationship of dynamic capabilities and some measures of financial performance profitability, cost reduction and inventory efficiency. It is clear that strategic asset such as processes, IT and customer and supplier readiness enhances online informational capabilities which then lead to higher financial performance. The findings show that basic experiential learning about international business occurs through exports, which expose a firm to global competition and provide interaction with foreign customers. The greater the intensity of a firm's export activity, the more frequently it engages in 
cross-border business transactions, and consequently the more international business knowledge it can accumulate. Export experience thus helps to evaluate the conditions in foreign locations and contributes to a firm's capability of entering and operating in foreign markets. It reduces costs of subsequent investment and of consecutive upgrades to higher commitment modes such as FDI (The capability of obtaining and decoding international market information can further enhance firms' awareness level about their competitive position vis-a' -vis future potential rivals in the global market. Hence, higher levels of export intensity enhance firms' capability and awareness to strategically engage with global competition. The limitations of these studies were that they focused more on export of strategic assets other than focusing firm's strategic assets capabilities.

Matanda and Schroder (2002) the purpose of the study was to investigate the effect of competitive capabilities of supply chain on business performance of horticultural industry in Zimbabwe. In order to achieve competitive advantage, a firm should consider both its internal capabilities and external environmental factors. So, what matters about gaining a competitive advantage is that a firm can create a specific competitive advantage according to the evaluation of its key capabilities that is based on value creating, rare, inimitable (differentiated from competitors), and complicated (nonsubstitutable) assets and resources referring to the resourcebased view. According to the results, marketing efficiency positively affects business performance. Cost and waste reduction positively affects business performance because of the major effect of waste reduction on business returns in perishable products. Technical efficiency significantly has negative relationship with business performance because of farmers' opinion to investment on buyers' required technical facilities as an unnecessary and excess factor. Innovation has negative relationship with business performance because of considering the innovation as a cost and not at least a shortterm advantage. Access to credit negatively relates with business performance because of its high cost and inequities in profit sharing between channel partners. This study used the survey method but doing case study on a specific firm as the analysis unit in order to obtain more detail information about presented conceptual model could have provided more information that is not available in survey method.

Swink et al. surveyed the effect of manufacturing competitive capabilities on plant performance. In order to investigate research objective, they focused on different industries in North America. Competitive capability is measured by cost efficiency, quality, delivery, process flexibility, and new product flexibility; and plant performance by market performance and customer satisfaction. According to the findings, flexibility of new product is a more important competitive capability. On the other hand, cost efficiency and process flexibility are either non-significantly or negatively associated with plant performance. Every capability of quality, delivery, and new product flexibility is associated with enhanced market performance. Also, delivery and quality capabilities are considerably related with more satisfaction of customer. In contrast, cost capability is negatively related with both aspects of business performance [26].

Firm performance can be defined as organizations being able to achieve objectives based on the constraints imposed by the limited resources. In this context, profit became one of the many indicators of performance. Lebans \& Euske (2006) defines the concept of firm performance as a set of financial and nonfinancial indicators which offer information on the degree of achievement of objectives and results. Firm performance can be judged by many different constituencies, resulting in many different interpretations of successful performance. Each of these perspectives of firm performance can be argued to be unique. Further, each organization has a unique set of circumstances, making performance measurement inherently situational.

Firm performance is based upon the idea that an organization is the voluntary association of productive assets, including human, physical, and capital resources, for the purpose of achieving a shared purpose (Barney, 2012). Those providing the assets will only commit them to the organization so long as they are satisfied with the value they receive in exchange, relative to alternative uses of the assets. As a consequence, the essence of performance is the creation of value. So long as the value created by the use of the contributed assets is equal to or greater than the value expected by those contributing the assets, the assets will continue to be made available to the organization and the organization will continue to exist. Firm performance measurement endorses a process perspective where the focus is on the internal process of quantifying the effectiveness and the efficiency of action with a set of metrics. The measures and indicators act as surrogates or proxies for organizational phenomena. Performance measurement represents management and control systems that produce information to be shared with internal and external users. Furthermore, as it encompasses all aspects of the business management cycle, this model constitutes a process for developing and deploying performance direction.

\section{Conclusion and Recommendations}

RDT assumes that bounded rationality applies for managers: the perception of the environment is directed and filtered by cognitive structures which are learnt through socialization and cognitive capacities to process information are seen as limited. Thus, it is not environment or resources that determine how organizational core groups decide or act, but cognitively and socially constructed environment. The organization is not viewed as simply adapting to a more or less dynamic environment. Rather RDT assumes that organizations create their environment too, change, disprove resistance among others.

Institutional theory has been applied to various dimensions of extant strategic literature. The influences of micro activities and the interplay between macro and micro activities in bringing success and efficiency to the 
institutionalization process have been given little attention as have been issues to do with strategic assets, competitive capabilities and firm performance the major areas covered in this paper. Equally, the concepts of institution and institutionalization possess disparate meanings in different disciplines with substantial variations among approaches, even within the organizational theoretical arena.

Dynamic capabilities can be criticized for the lack of precise definition, empirical grounding, and measurement and attempts to measure dynamic capabilities have used distant proxies. The poor understanding of dynamic capabilities and the lack of a measurable model makes it difficult to study how dynamic capabilities can be used in actionable managerial decision making and in regards to strategic assets, competitive capabilities and firm performance. The lack of universally accepted definition is because dynamic capabilities have been explained in terms of theoretical underpinnings. Because lack of a universally accepted definition, there is no universal way of measuring, and no universal unit of measurement of dynamic capabilities before they demonstrate themselves. Dynamic capabilities can also be criticized for their lack of empirical grounding, and measurement and attempts to measure dynamic capabilities and how they relate to strategic assets and firm performance have used distant proxies.

Only strategically important and useful resources and competencies should be viewed as sources of competitive advantage. Strategic assets are, the set of difficult to trade and imitate, scarce, appropriable and specialized resources and capabilities that bestow the firm's competitive advantage. Core competencies are distinctive, rare, valuable firm-level resources that competitors are unable to imitate, substitute or reproduce. Competence creation defines and analyses the markets, product and service. Competence realization involves the execution of services, procurement, and production. Competence transaction involves market logistics, order fulfillment and maintenance.

Intangible resources are more likely to be a source of sustained competitive advantage rather than tangible ones, these should not be 'locked' inside a business unit but should be available for reuse by other parts of firm wherever a potential use yielding higher returns can be identified. Redesigning a firm's processes, activities and routines can enable efficient and effective usage of resources and capabilities that can achieve sustainable competitive advantage. The importance of capabilities and suggest that a firm can gain competitive advantage from its ability to apply its capabilities to perform important activities within the firm. The ability to learn and create new knowledge is essential for gaining competitive advantage.

\section{References}

[1] Acedo, F. J., Barroso, C. and Galan, J. L. (2006): "The resource-based theory: Dissemination main trends", Strategic Management Journal, 27 (7), 621-636.
[2] Anderse'n, J. (2007): "How and what to imitate? A sequential model for the imitation of competitive advantages", Strategic Change Journal, 16 (6), 271-279.

[3] Ambrosini, V., Bowman, C. and Collier, N. (2009). Dynamic capabilities: an exploration of how firms renew their resource base. British Journal of Management.

[4] Barney, J. B (2012): "Organizational culture: can it be a source of sustained competitive advantage?" Academy of Management Review. 11 (3), 656-665.

[5] Barney, J. B. and Hesterly, W. S. (2008), Strategic Management and Competitive Advantage: Concepts and Cases, Pearson/Prentice-Hall, Upper Saddle River, NJ.

[6] Baumol, W. J., Litan, R. E., \& Schramm, C. J. (2009). Good capitalism, bad capitalism, and the economics of growth and prosperity. New Haven, CT: Yale University Press.

[7] Bruton, Garry D., Ahlstrom, D. \& Li, H. (2010). Institutional Theory and Entrepreneurship: Where Are We Now and Where Do We Need to Move in the Future? 1042-2587@ 2010 Baylor University.

[8] Carmen, C. O., Fernando, M., Ramon, V. C. (2003). Intangible Resources and Strategic Orientation of Companies: An Analysis in the Spanish Context, Journal of Business Research, 56, 95-103.

[9] Chang HR, Hou JJ (2007). Organizational change and dynamic capabilities; A case of high-tech company. Industrial Forum, 9 (1), 15-29.

[10] Clemens, E. S. and Cook, J. (2005). Politics and institutionalism: Explaining durability and change. Annual Review of Sociology, 25: 441-466.

[11] Daft, R. L. (2003). Organizational theory and design. Cincinnati, OH: South-Western.

[12] Davis, G. F., \& Cobb, J. A. (2010). Research in the Sociology of Organizations Chapter 2 Resource dependence theory: Past and future: Emerald Group Publishing Limited.

[13] Eisenhardt, K. M. and J. A. Martin, (2010):"Dynamic capabilities: What are they?" Strategic Management Journal, 21 (2), 1105-1121.

[14] Foss, N. J. and Knudsen, T. (2009). The Resource-Based Tangle: Towards a Sustained Explanation of Competitive Advantage, Institute for Industry Economy, working paper 2008-9.

[15] Galbreath J. (2004). Which Resources Matter The Most to Firm Success? An Exploratory Study of Resource-based Theory, Technovation.

[16] Helfat, C. E., and Raubitschek, R. S. (2007). Product sequencing: Co-evolution of knowledge, capabilities and products. Strategic Management Journal, 21 (10-11): 961980.

[17] Hessels, J. \& Terjesen, S. (2010). 'Resource dependency and institutional theory perspectives on direct and indirect export choices.' Small Business Economics, 34: 2, 203-20.

[18] Johanson, J. Vahlne, J-E. (2009). The Uppsala Internationalization Process Model Revisited From liability of foreignness to liability of outsidership. Journal of International Business Studies. 40 (9) s. 1411-1431. 
[19] Jepperson, R. L. (2001). The Development and Application of Sociological Neoinstitutionalism, European University Institute, Florenz, EUI Working Papers RSC 2001/5.

[20] Lebans, M., Euske, K. (2006), “A conceptual and operational delineation of performance", Business Performance Measurement, Cambridge University Press.

[21] Ordaz, C. C., Alcazar, F. M., and Cabrera, R. V. (2003). Intangible Resources and Strategic Orientation of Companies, an Analysis in the Spanish Context, Journal of Business Research, 56, 95-103.

[22] Porter, M. E (2011): "Towards a dynamic theory of strategy", Strategic Management Journal, 12 (1), 95 - 117.

[23] Prescott, J. E. (2011): The evolution of competitive intelligence, in Hussey, D. E. (Ed.), International Review of Strategic Management, Wiley, Chichester. NY.

[24] Rainbird, M. (2010):”A framework for operations management: the value chain", International Journal of Physical Distribution and Logistics Management, 34 (2), 1225 .
[25] Santangelo, G. and Meyer, K. E. (2011). 'Extending the internationalization process model: increases and decreases of MNE commitment in emerging economies'. Journal of International Business Studies, 42, 894-909.

[26] Swink, M., \& Song, M. (2007). Effects of marketingmanufacturing integration on new product development time and competitive advantage. Journal of Operations Management, 25, 203-217.

[27] Teece DJ (2007). Explicating dynamic capabilities: the nature and microfoundations of (sustainable) enterprise performance, Strategic Management Journal, 28 (13): 1319-50.

[28] Woiceshyn J, Daellenbach U (2005). Integrative capability and technology adoption: evidence from oil firms. Industrial and Corporate Change, 14 (2), 307.

[29] Zahra S, Sapienza H, Davidsson P (2006). Entrepreneurship and dynamic capabilities: a review, model and research agenda, Journal of Management Studies, 43, pp. 917-955.

[30] Zahra, S. A. and George, G. (2002). Absorptive capacity: A review, reconcepualisation, and extension. Academy of Management Review, 27 (2): 185-203. 